\title{
A finite velocity simulation of sedimentation behaviour of flocculating particles - A real-time model evaluation
}

\author{
Nomcebo P Sithebe, Bhekizizwe G Methula and Evans MN Chirwa* \\ Water Utilisation Division, Department of Chemical Engineering, University of Pretoria, Pretoria 0002, South Africa
}

\begin{abstract}
A mechanistic velocity model is developed to simulate the behaviour of flocculating colloidal particles in turbid water. The current model is based on one-dimensional mass transport in the vertical direction as an integrated form of the model derived by Ramatsoma and Chirwa. The percentile removal model achieved more accurate simulation of physical experimental data than known models such as the Ozer's model and San's model. In this study, an integrated velocity form was used to estimate flocculent settling velocity of fine suspended particles under near quiescent conditions. Model closeness to experimental measurements was determined as a function of the sum of squares error (SSE) between model data and experimental data. The proposed velocity model offers a distinctive advantage over the interpolated-isopercentile based models which are prone to numerical errors during interpolation. The results contribute towards the ultimate goal of achieving full automation of the design of gravitational particle separation devices for water and wastewater treatment.
\end{abstract}

Keywords: flocculation model, semi-empirical system, velocity integrated model, continuity model

\section{NOMENCLATURE}

fitting parameter in San's model (dimensionless)

the model fitting parameters in Özer's model (dimensionless) ( $i=1,2$, and 3$)$

$\beta \quad$ fitting parameter in San's model (dimensionless)

a fitting parameter in Piro and co-workers' model and Je and Chang's model (dimensionless)

$\mathrm{b}$ fitting parameter in Piro and co-workers' model and Je and Chang's model (dimensionless)

$D \quad$ depth travelled by particle during settling $(L)$

$D_{z} \quad$ dispersion coefficient in the vertical direction $\left(L^{2} T^{1}\right)$.

$h, H$ ordinate representing depth

$k \quad$ fitting parameter in San's model (dimensionless)

$\mathrm{n} \quad$ fitting parameter of the power law model and exponential model (dimensionless)

$P \quad$ percentage removal $\left(1-X_{j} / X_{o}\right) \times 100$

$P$ percentage remaining in suspension $\left(X_{j} / X_{0}\right) \times 100$

$r_{i} \quad$ semi-empirical optimisable parameters of Ramatsoma and Chirwa's model $(i=1,2$, and 3$)$

time of settling $(T)$

ordinate representing time

vertical water velocity $\left(L T^{1}\right)$

settling velocity $\left(L T^{1}\right)$

flocculent settling velocity $\left(L T^{1}\right)$,

solids concentration in the power law model and exponential model $\left(M L^{-3}\right)$

$X_{.} \quad$ suspended solids concentration in layer $j\left(M L^{-3}\right)$

$X_{0} \quad$ initial concentration in the column $\left(M L^{-3}\right)$

$\mathrm{z}, \mathrm{Z} \quad$ vertical distance $(L)$

\section{INTRODUCTION}

In water and wastewater treatment facilities, the mass transport and behaviour of fine-grained cohesive sediments is influenced mainly by flocculation effects and nominal settling velocities of particles. Hence the understanding of batch settling processes of flocs is fundamental for effective thickener/clarifier design and control. The behaviour of flocculating particles and settling trajectories of individual particles is very complex. Flocculation effects and velocities are usually investigated using jar tests to establish dose, and settling columns to evaluate the flocculation behaviour.

Constant spatial and temporal variations and fluctuating initial conditions in physical sedimentation systems result in difficulty and uncertainty in the predictions of medium- and long-term behaviour of the settling particles (Xu et al., 2008; Mikkelsen et al., 2005). During the design of sedimentation tanks, data from settling columns are interpreted by a graphical technique. Firstly, samples are collected from different column depths at different times and are analysed for total suspended solids concentration (TSS). The batch settling data is then utilised to compute iso-percentage removal profiles as a function of time and depth. From the graphs, one can predict or calculate the removal efficiency, overflow rate and settling velocities of particles. However, it is common practice in industry to manually construct the isopercentile curves due to their nonlinear nature. This practice is tedious, inaccurate, and susceptible to human error.

There is also the problem of irreproducibility since no two different technicians can construct exactly the same curves. When using currently proposed models to fit the percentage removal data, some fit the data well only at short retention times and others tend to violate the physical meaning of settling data profiles (Je and Kim, 2002). The use of inaccurate settling equations could lead to significant errors of aggregate properties.

This article evaluates a model based mainly on the prediction of the settling velocities derived as the integrated form 
of the rule-based model. Equipped with a robust velocity model, the analysis could then analytically revert back to the isopercentile trajectory analysis without the need for analysis of the physical data from a settling column. This approach will introduce accuracy and reproducibility, and will save time in the sedimentation zone and clarifier designs.

\section{THEORETICAL BACKGROUND}

\section{Existing models for iso-percentile removal profiles}

Modelling of the particle settling processes relies on the understanding of the dynamics of the flocculation system, variability of sediment concentration and composition, floc size, microbiological activity, salinity and temperature (Khelifa and Hill, 2006). Most current models assume a one-dimensional flow of particles in space and are therefore modelled by a set of linear differential equations. However, the true nature of settling particles is highly nonlinear and is influenced by fluctuating initial conditions.

Several analytical systems have been suggested for simulation of iso-percentile concentration or removal profiles. Any suggested model may pass or fail on mathematical grounds or inconsistency with physical systems. According to Je and Kim (2002), a model can fit and predict flocculent settling profiles, only if it does not violate the physical meanings of flocculent settling curves. These conditions have been re-stated in this paper under Ramatsoma and Chirwa's modelling review (Eqs. (15)-(19)).

Available iso-percentiles removal models from literature include Ozer's model (1994), Sans' model (1989), Berthouex and Stevens (1982), rule-based model by Montgomery (1979), a combination of the rule-based model with regression by Hayes (1992) and the power law model by Piro and coworkers (2011). Amongst the four that were reviewed by Je and Kim (2002), only the Berthouex and Stevens (1982) model violated the criterion of constraint for settling particles and could not fit data at long settling times.

The best simulation results have so far been obtained using the three empirical models below, i.e, Özer's (1994) model, San's (1989) model and lately Piro and coworkers' (2011) model. Ozer's (1994) analytical approach was based on the observation of rainfall intensity duration frequency. The nonlinear relationship between the rainfall intensity, duration, and frequency of occurrence is viewed as a multiplicative model. Hence the author utilised this analogy to model the relationship between concentration percentage, $P$ ", remaining in suspension with time and column depth as follows:

$$
\begin{aligned}
& P^{\prime \prime}=\alpha_{1} D^{\alpha_{2}} t^{\alpha_{3}} \\
& P^{\prime \prime}=\alpha_{1} D^{\alpha_{2}} t^{\alpha_{3}}-1
\end{aligned}
$$

where:

$$
\begin{aligned}
& P^{\prime \prime}=\text { percentage remaining }\left(X_{j} / X_{o}\right) \times 100 \\
& X_{o}=\text { initial concentration in the column }\left(M L^{-3}\right) \\
& D=\text { depth travelled by particle during settling }(L) \\
& t=\text { time of settling }(T)
\end{aligned}
$$

The parameters $\alpha_{1}, \alpha_{2}, \alpha_{3}=$ fitting parameters for the isopercentile lines. Sans' (1989) expressed the per cent total suspended solids (TSS) remaining in tank, $P^{\prime \prime}$, as a function of settling time $(T)$ and depth $D(L)$ in a quiescent settling column (Eq. (3)).

$$
P^{\prime \prime}=\frac{t^{\beta}}{\alpha D^{k}+t^{\beta}}
$$

where:

$\alpha, \beta$, and $k=$ optimisable parameters.

San's and Özer's models have been shown to comply with the assumptions stated by Je and Kim (2002).

Piro et al. (2011) developed the simplest settling model presented by a power law function (Eq. (4)), where the removal of particles is expressed as a function of time at a particular distance from the top of a water column.

$$
h=\bar{a} t^{\bar{b}}
$$

where:

$h$ is the depth $(L), t(T)$ is the residence time

$\bar{a}$ and $\bar{b}$ are empirical parameters.

If a derivative of distance is taken against time, the term decays to the velocity term (Eq. (5)).

$$
\frac{d h}{d t}=a b t^{b-1}
$$

Based on this power law, the settling of the particles is discrete (Type I settling) if $\bar{b}=1$ and is flocculent if $\bar{b}>1$ and $\bar{a}$ is the velocity term $\left(L T^{1}\right)$.

\section{Existing settling velocity models}

During settling, suspended particles coalesce with smaller solids to form larger flocs. Settling velocities of cohesive sediments are not uniquely related to particle sizes as in Stokes' law because the average density of a floc and surface area properties of the particles are time variant and highly irregular. The transport rate depends on floc size, floc density, fractal dimension and gravity (Lee et al., 2002).

In earlier studies by Cho et al. (1993), the so called 'solid flux' concept for settler calculation was introduced. So far, 2 empirical models have been utilised successfully for solid flux settler design. These include the power law model (Eq. (6)) and the exponential model (Eq. (7)):

$$
\begin{aligned}
& v=k x^{-n} \\
& v=k \exp (-n x)
\end{aligned}
$$

where:

$k, x$ and $n$ are the maximum settling velocity, solids concentration and model parameter, respectively

The exponential model is reasonable in dilute concentrations but is more complicated in designing a settler. The power law model on the other hand becomes infinite in a dilute concentration range.

Je and Chang (2004) derived a simple velocity formula (Eq. (8)) based on Ozer's flocculation model and a one-dimensional continuity equation. The equation could predict the transport of re-suspended sediments introduced by dredging operations. The same analogy was followed in this paper, but with a more reliable flocculation model.

$$
V_{s}=\frac{-a Z}{(b+1) \cdot T}
$$


where:

$Z, T, a$ and $b$ are the settling column depth, time and parameters, respectively

\section{The Ramatsoma and Chirwa Model reviewed}

Ramatsoma and Chirwa's semi-empirical model was based on the original assumptions by Özer (1994) to arrive at an analogous model with optimisable parameters $r_{1}, r_{2}, r_{3}$ (Ramatsoma and Chirwa, 2012).

$$
H_{i}=H_{\max }+r_{1} P^{2} t^{r_{2}}-r_{3} P^{2} t
$$

where:

$$
\begin{aligned}
& r_{1}, r_{2} \text { and } r_{3} \text { are semi-empirical optimisable parameters } \\
& H_{i}=\text { height of sampling points } \\
& H_{\max }=\text { design height of proposed tank } \\
& P \quad=\text { percentage removal }\left(1-X_{j} / X_{o}\right) \times 100 .
\end{aligned}
$$

On rearranging Eq. (9) and writing it with the full range of parameters:

$$
P=\left(\frac{-D}{r_{1} t^{r_{2}}-r_{3} t}\right)^{0.5}
$$

where the following parameter constraints apply within the meaningful physical space with real mass concentration:

$$
\begin{aligned}
& D=H_{\text {max }}-H_{i} \\
& r_{1}<0 \\
& r_{2}>0 \\
& 0 \leq r_{3} \sim \frac{0.1}{r_{2}}
\end{aligned}
$$

The right hand side of Eq. (14) was used as a first guess of the value of $r_{3}$ during parameter optimisation. Eq. (10) is then utilised to construct iso-percentile removal profiles for the settling process. Ramatsoma and Chirwa ensured that the model adheres to the physical meanings of a settling particle as stated by Je and Kim (2002).

Physical conditions considered during the simulation of sedimentation tanks should satisfy the following conditions at any layer $j$, time $t$ and depth $D$ : (i) the settling velocity should always be positive, (ii) TSS concentration remaining should increase with depth, (iii) TSS concentration remaining should decrease with time, and (iv) variation of TSS concentration remaining should not increase with depth. These conditions are represented by the following equations, Eqs. (15)-(19).

$$
\begin{aligned}
& X_{j}=f(t, D) \\
& \frac{\partial D}{\partial t} \geq 0 \\
& \frac{\partial X_{j}}{\partial D} \geq 0 \\
& \frac{\partial X_{j}}{\partial t} \leq 0 \\
& \frac{\partial^{2} X}{\partial D^{2}} \leq 0
\end{aligned}
$$

where:

$X_{j}=$ suspended solids concentration (TSS) $\left(M L^{-3}\right)$

$D=$ distance travelled by particle $(L)$

$t=$ time of travel $(T)$

\section{Proposed flocculent velocity model derivation}

A general sediment transport equation in a quiescent settling column is described by a one-dimensional continuity equation, Eq. (20) (Je and Chang, 2004).

$$
\frac{\partial C}{\partial t}=\frac{\partial\left(D_{z} \partial C\right)}{\partial Z^{2}}-\frac{\partial\left(U_{z} C\right)}{\partial Z}+\frac{\partial\left(V_{s} C\right)}{\partial Z}
$$

where:

$t=$ settling time $(\mathrm{h})$

$Z=$ settling column depth $(\mathrm{m})$

$U_{Z}=$ vertical water velocity $(\mathrm{m} / \mathrm{h})$

$V_{S}=$ flocculent settling velocity $(\mathrm{m} / \mathrm{h})$

$D_{Z}=$ dispersion coefficient in the vertical direction $\left(\mathrm{m}^{2} / \mathrm{h}\right)$

In a batch column with quiescent flow, the continuity equation can be further simplified by applying the following assumptions:

- There is no vertical flow passing through the settling column

- There is no vertical dispersion within the settling column

- Since there is no bottom re-suspension, additional source terms do not apply

Using the above assumptions Eq. (20) is simplified to Eq. (21):

$$
\frac{\partial C}{\partial t}=\frac{\partial\left(V_{s} C\right)}{\partial Z}
$$

Eq. (21) is then integrated with respect to depth, $z$, to give Eq. (22):

$$
V_{s} C=-\int \frac{\partial C}{\partial t} d z
$$

On substituting Ramatsoma and Chirwa's flocculation model into Eq. (22):

$$
V_{s}\left(\frac{-D}{r_{1} t^{r_{2}}-r_{3} t}\right)^{0.5}=-\int \frac{\partial}{\partial t}\left(\frac{-D}{r_{1} t^{r_{2}}-r_{3} t}\right)^{0.5} d z
$$

Integrating Eq. (23) gives the settling velocity equation as a function of time and depth:

$$
V_{s}=-\frac{D^{1.5}}{3}\left(r_{1} r_{2} t^{r_{2}-1}-r_{3}\right)\left(\frac{1}{r_{1} t^{r_{2}}-r_{3} t}\right)^{1.5}
$$

This Eq. (24) becomes important in determining the velocity of particles that are $100 \%$ removed at given residence times and tank depth.

\section{MATERIALS AND METHODS}

\section{Standard batch settling column}

Figure 1 shows a simple batch column that was used in the collection of physical data. A $100 \ell$ mixing tank was used together with a stirrer to mix water with a ferric chloride $\left(\mathrm{FeCl}_{3}\right)$ coagulant (Experiments 1-5) and an aluminium sulphate $\left(\mathrm{Al}_{2}\left(\mathrm{SO}_{4}\right)_{3}\right)$ coagulant (Experiments 6-7) and dry clay soil (Table 1). A $5 \ell$ beaker was used to transfer the dilute suspension from the mixing tank to the column $(200 \mathrm{~cm} \times 19 \mathrm{~cm}$ diameter $)$. Sampling bottles were used to withdraw samples from the column at any given time.

\section{Simulation of dirty water}

In the simulation of dirty water, $90 \ell$ of water was poured into 


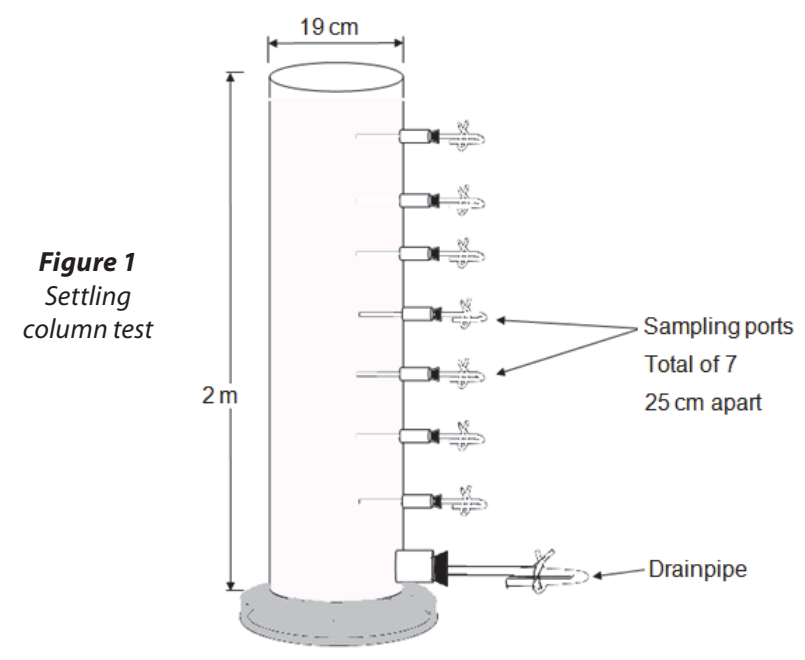

the mixing tank and approximately $400 \mathrm{~g}$ of dry clay soil was added to make the water dirty. The coagulant was then added and the stirrer was switched on for $2 \mathrm{~min}$ at $180 \mathrm{r} / \mathrm{min}$. The colloidal suspension was then carefully transferred into the test column. Immediately after filling the column, 2 to $3 \mathrm{~min}$ were allowed before starting data collection. Samples from the 7 sampling ports were withdrawn at different intervals. Table 1 shows the experiments that were performed.

Samples were analysed by a HACH Turbidity Meter (Model 2100 N, Hatch Company, Loveland, CO) and the recorded values in NTUs were converted to the mass concentration using the equation $\ln (\mathrm{TSS})=1.5 \ln (\mathrm{NTU})+0.15$, based on the 10-point calibration line from a TSS versus NTU data set $\left(R^{2}=0.97\right)$ (Packman et al., 1999). The total suspended solids (TSS) were measured in the range $10-300 \mathrm{mg} / \ell$ as dry weight of suspended solids trapped on a $0.45 \mu \mathrm{m}$ micro-pore membrane filter (APHA, 2005).

\begin{tabular}{|l|c|c|}
\hline \multicolumn{3}{|c|}{ TABLE 1 } \\
\hline $\begin{array}{l}\text { Experiment } \\
\text { No. }\end{array}$ & $\begin{array}{c}\text { Coagulant } \\
\text { concentration (mg/l) })\end{array}$ & $\begin{array}{l}\text { Average initial solids } \\
\text { concentration (NTU) }\end{array}$ \\
\hline 1 & 10 & 195 \\
\hline 2 & 50 & 208 \\
\hline 3 & 70 & 170 \\
\hline 4 & 68 & 112 \\
\hline 5 & 70 & 141 \\
\hline 6 & 10 & 235 \\
\hline 7 & 15 & 242 \\
\hline
\end{tabular}

\section{Numerical analysis and optimisation}

Iso-percentile lines were calculated by fitting the model (Eq. (10)) to interpolated values of the chosen percentiles from experimental data collected from the settling columns. Data interpolation and curve fitting was done using the programming platform, Octave (GNU Octave Version 3.4.2, Free Software Foundation, Boston, MA). Individual iso-percentile removal profiles were calculated from the geometrical relationship between the percentage removal and column height at any particular time according to the model chosen.

\section{RESULTS AND DISCUSSION}

\section{Evaluation of settling data}

Suspended solids concentration data was collected from settling columns in experiments run for $80 \mathrm{~min}$ in a $2.0 \mathrm{~m}$ column. An example of the results from an optimum dose of $10 \mathrm{mg} / \ell$ $\mathrm{Al}_{2}\left(\mathrm{SO}_{4}\right)_{3}$ is shown in Table 2 and the corresponding percentage removal data is shown in Table 3 . The results collected were characteristic of most data from similar water samples.

\begin{tabular}{|c|c|c|c|c|c|c|c|}
\hline \multicolumn{8}{|c|}{$\begin{array}{c}\text { TABLE } 2 \\
\begin{array}{c}\text { Suspended solids concentration data from settling column test at } X_{o}=235 \pm 4 \mathrm{NTU} \\
\left.\text { (coagulant dose }=10 \mathrm{mg} / \ell \mathrm{Al}_{2}\left(\mathrm{SO}_{4}\right)_{3}\right)\end{array}\end{array}$} \\
\hline \multirow{2}{*}{$\begin{array}{l}\text { Distance, } \boldsymbol{H} \\
(\mathrm{m})\end{array}$} & \multicolumn{7}{|c|}{ Concentration at different times } \\
\hline & $3 \min$ & $10 \mathrm{~min}$ & $20 \mathrm{~min}$ & $30 \mathrm{~min}$ & $40 \mathrm{~min}$ & $60 \mathrm{~min}$ & $80 \mathrm{~min}$ \\
\hline 1.75 & 126 & 76 & 51 & 32 & 21 & 16 & 11 \\
\hline 1.5 & 132 & 80 & 55 & 42 & 26 & 20 & 14 \\
\hline 1.25 & 154 & 96 & 58 & 45 & 33 & 29 & 17 \\
\hline 1 & -- & 103 & 60 & 47 & 42 & 32 & 23 \\
\hline 0.75 & -- & 113 & 64 & 49 & 43 & 39 & 24 \\
\hline 0.5 & -- & 118 & 67 & 56 & 52 & 32 & 27 \\
\hline 0.25 & -- & 122 & 74 & 65 & 52 & 39 & 31 \\
\hline
\end{tabular}

\begin{tabular}{|c|c|c|c|c|c|c|c|}
\hline & $r$ cent $r$ & $\begin{array}{l}\text { val data } \\
\text { (coagu }\end{array}$ & $\begin{array}{r}\text { TAB } \\
\text { m settl } \\
\text { t dose }=\end{array}$ & $\begin{array}{l}3 \\
\text { column } \\
\mathrm{mg} / \mathrm{l} \mathrm{Al}\end{array}$ & $\begin{array}{l}t \text { at } X_{o}= \\
\left.\left.()_{4}\right)_{3}\right)\end{array}$ & \pm 4 NTU & \\
\hline Distance, $H$ & & & oval per & tage $(P)$ a & fferent $t$ & & \\
\hline (m) & $3 \min$ & $10 \mathrm{~min}$ & $20 \mathrm{~min}$ & $30 \mathrm{~min}$ & $40 \mathrm{~min}$ & $60 \mathrm{~min}$ & $80 \mathrm{~min}$ \\
\hline 1.75 & 46.3 & 67.8 & 78.5 & 86.4 & 91.1 & 93.4 & 95.2 \\
\hline 1.5 & 44.0 & 65.8 & 76.4 & 82.3 & 88.8 & 91.6 & 94.2 \\
\hline 1.25 & 34.6 & 59.2 & 75.3 & 81.0 & 85.9 & 87.8 & 92.7 \\
\hline 1 & -- & 56.2 & 74.3 & 80.2 & 82.2 & 86.4 & 90.3 \\
\hline 0.75 & -- & 51.8 & 72.8 & 79.2 & 81.7 & 83.3 & 89.7 \\
\hline 0.5 & -- & 49.8 & 71.3 & 76.2 & 77.9 & 86.4 & 88.5 \\
\hline 0.25 & -- & 47.9 & 68.7 & 72.3 & 77.9 & 83.4 & 87.0 \\
\hline
\end{tabular}



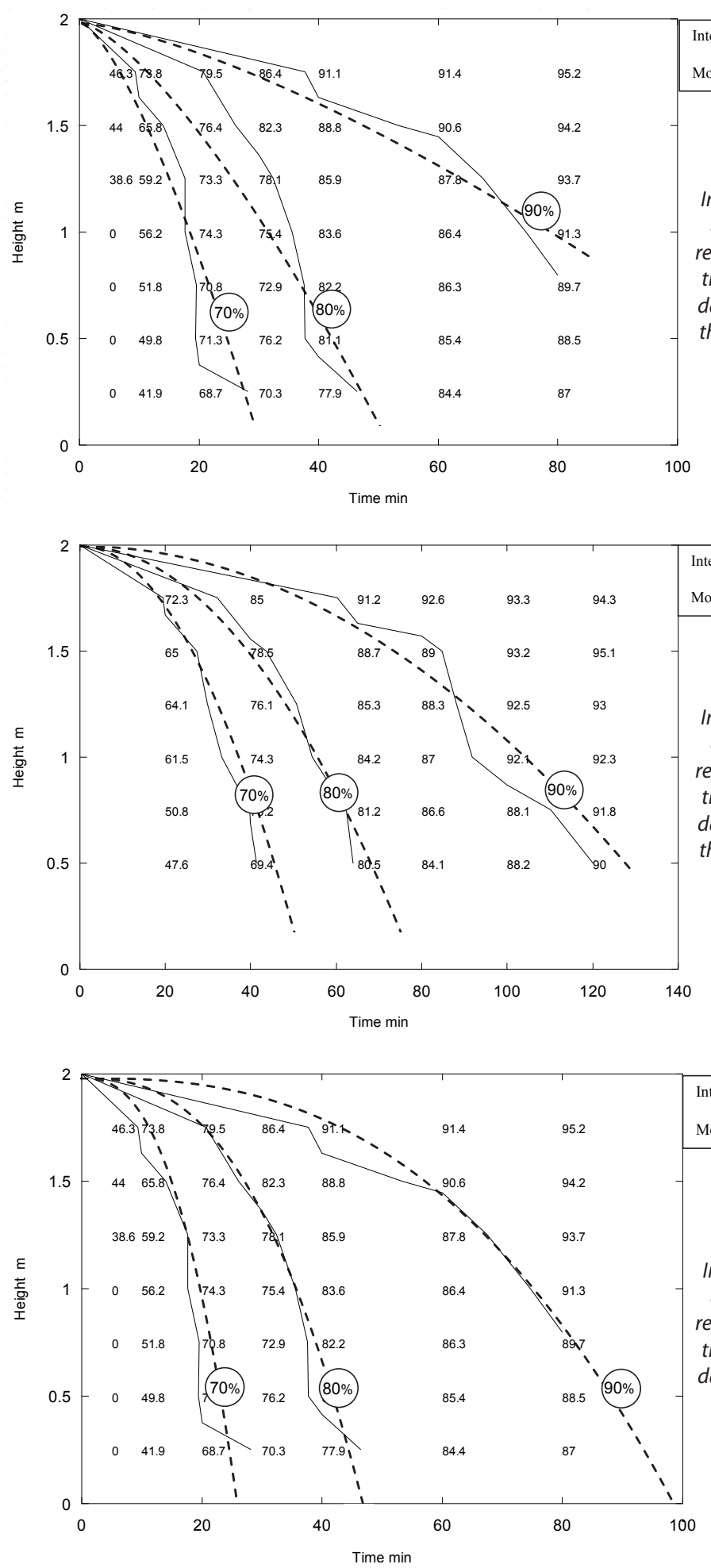

Examples are found in a range of technical texts including Tchobanoglous et al. (2003), Reynolds and Richards (1996), Sawyer et al. (2003), and others. The conventional method of analysing these data is by calculating percentage removals (usually by spreadsheet), plotting interpolation points, followed by plotting smoothed iso-percentile lines using a model.

\section{Interpolation and simulation}

Before simulation of iso-percentile lines, a computational
Interpolation $_{\text {Model }^{--}}$
Figure 2

Figure 2

Interpolation results and iso-percentile removal profiles from the $6^{\text {th }}$ experimental dataset simulated by the Ramatsoma and Chirwa model
Model - - .

Figure 3 Interpolation results and iso-percentile removal profiles from the $7^{\text {th }}$ experimental dataset simulated by the Ramatsoma and Chirwa mode

Interpolation Model _ -

Figure 4 Interpolation results and iso-percentile removal profiles from the $6^{\text {th }}$ experimental dataset simulated by the San model

algorithm was used to generate the raw percentage removal data points. Normally, this exercise is done by hand in the real industry context. The automated interpolation was conducted across the grid in the zero and $90^{\circ}$ directions from a given data point. The accuracy of the interpolated data set is critical to the accuracy of the final percentiles since these provide the fixed scaffold points for parameter optimisation and therefore determine the degree of the overall model accuracy. For this reason, the improvement of the interpolation procedure is regarded in this study as the key to achieving the parameters of the highest possible accuracy for physical design of clarifiers.

The model presented in Eq. (9) and (10) was then used to provide the smooth lines to approximate the trajectory of constant percentage removal. The model was tested against data collected in the laboratory and previous data presented in textbooks. Representative data from practical data collected in the laboratory is presented for example in Figs. 2, 3, 4 and 5.

Typically, iso-percentile plots do not fit all areas of the data equally well. In practice, the accuracy of the interpolation is only seen after simulation of the whole data set and is evaluated holistically. This process can be improved by including 2 or more data points from the surrounding iso-percentile line and then establishing a point and using statistical means to improve accuracy.

In the given example data sets (Figs. 2-5), a reasonable fit of model data to interpolation (real) data is observed in Fig. 3 using Ramatsoma and Chirwa's model. However in Fig. 2, Ramatsoma and Chirwa's model underestimates the interpolated removal profiles at the top three column ports. The reason for this may be due to insufficient flocculation having occurred in the first few minutes for the particles to behave in the manner consistent with theoretical flocculent particles. In Fig. 4, Sans' model overestimates the $90 \%$ profile within the first 40 min. In Fig. 5, Sans' model also overestimates the $70 \%, 80 \%$ and $90 \%$ removal profiles, with the $90 \%$ profile fitting only between $60 \mathrm{~min}$ and $80 \mathrm{~min}$. This inconsistency may be due to the limited ability of empirical models.

\section{Error analysis}

In order to check the accuracy or performance of the model, the interpolated values were used as the real values and compared with the predicted model values. In an earlier study, Je and Kim (2002) observed better performance of mechanistic models over 


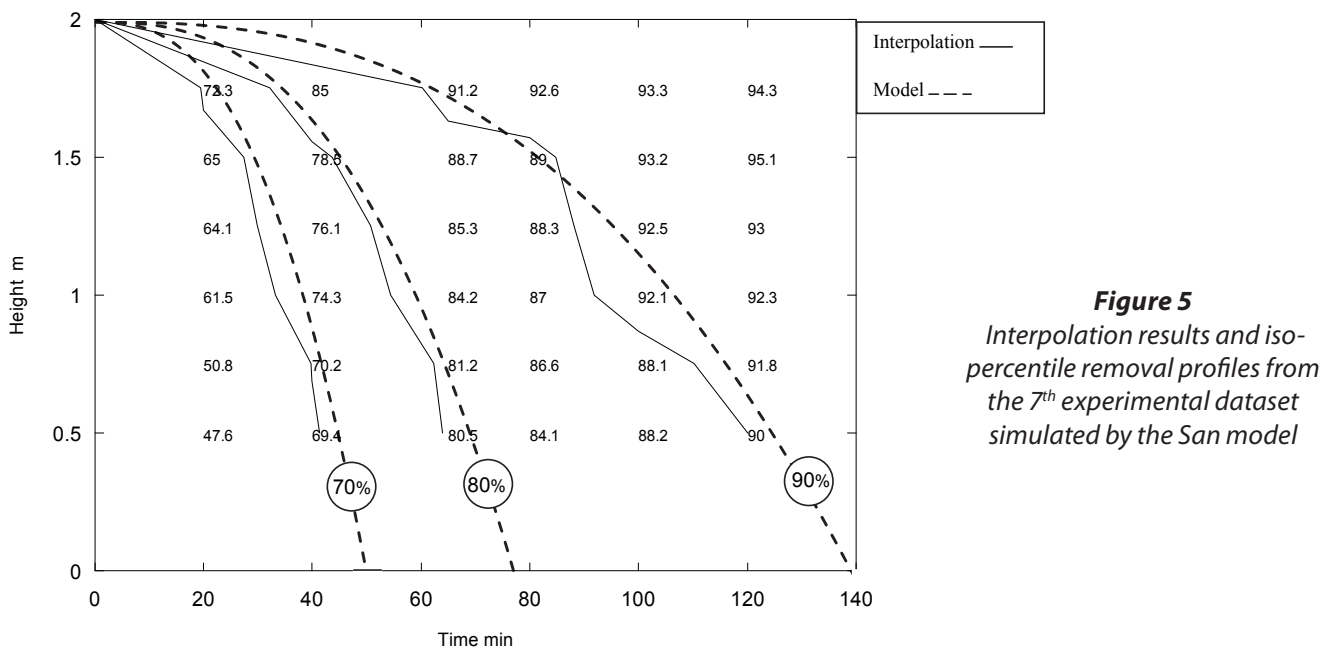

empirical models under certain data ranges. The lack of fit of empirical models was later attributed to limited range as they failed to approximate data around the outer boundaries of the calibrated areas. Another semi-empirical model, the Berthouex and Stevens' model, was the second best for fitting the data but it was later rejected as it violates the flocculent sedimentation rules stated in Eqs. (18) and (19).

The fitting of the datasets was compared with San's model since it is consistent with the physical basis of flocculent sedimentation. It is also among the best fits of the literature-based models, as concluded by Je and Kim (2002). As a result the proposed model is compared to San's model. The model fitness is determined by the statistical data presented in Table 4 .

Visual inspection of the iso-percentile computations using the semi-empirical model derived by Ramatsoma and Chirwa achieves a reasonably accurate representation of the per cent removals. The accuracy of the model is shown in Table 4 for Ramatsoma and Chirwa's model versus San's model, and in Tables 5 and 6 for Ramatsoma and Chirwa's versus Özer's model. Comparison of the sum of squares error $\left(\mathrm{SS}_{\mathrm{E}}\right)$ between

TABLE 4

Model performance compared against San's model using experimental data with $10 \mathrm{mg} / \mathrm{\ell} \mathrm{Al}\left(\mathrm{SO}_{4}\right)_{3}$ coagulant and literature data (Source: this study)

\begin{tabular}{|l|c|c|c|c|c|c|c|c|}
\hline & \multicolumn{3}{|c|}{ Ramatsoma and Chirwa's model } & \multicolumn{4}{c|}{ San's model } \\
\hline Data source & $r_{1}$ & $r_{2}$ & $r_{3}$ & $\mathrm{SS}_{\mathrm{E}}$ & $\boldsymbol{a}$ & $\boldsymbol{b}$ & $\boldsymbol{k}$ & $\mathrm{SS}_{\mathrm{E}}$ \\
\hline Experiment 6 & -0.2 & 1.4 & 71 & 1.21 & 0.008 & -0.06 & 0.23 & 1.95 \\
\hline Experiment 7 & -0.009 & 2.0 & 118 & 0.74 & 1.91 & 0.55 & -0.44 & 0.81 \\
\hline Reynolds \& Richards (1996) & -0.027 & 1.5 & 540 & 0.30 & 0.043 & -0.60 & -0.23 & 0.20 \\
\hline Peavy et al. (1985:122) & -0.02 & 1.3 & 79 & 0.15 & 0.321 & -0.30 & -0.23 & 0.39 \\
\hline
\end{tabular}

TABLE 5

Model performance compared against Özer's model using experimental data with $10 \mathrm{mg} / \ell \mathrm{FeCl}_{3}$ coagulant (From: Ramatsoma and Chirwa, 2012)

\begin{tabular}{|l|c|c|c|c|c|c|c|c|}
\hline & \multicolumn{3}{|c|}{ Ramatsoma and Chirwa's model } & \multicolumn{4}{|c|}{ Özer's model } \\
\hline $\begin{array}{l}\text { Experiment } \\
\text { No. }\end{array}$ & $\begin{array}{c}r_{1} \\
\left(\times 10^{-3}\right)\end{array}$ & $r_{2}$ & $\begin{array}{c}r_{3} \\
\left(\times 10^{-3}\right)\end{array}$ & $\mathrm{SS}_{\mathrm{E}}$ & $a_{1}$ & $a_{2}$ & $a_{3}$ & $\mathrm{SS}_{\mathrm{E}}$ \\
\hline 1 & -0.94 & 2.141 & 0.00328 & 3.62 & 4.1 & 0.45 & -0.53 & 9.58 \\
\hline 2 & -0.7 & 2.09 & 0.000041 & 1.71 & 4.35 & 0.46 & -0.512 & 3.23 \\
\hline 3 & -0.7501 & 2.2 & 0.02911 & 3.58 & 4.5 & 0.69 & -0.56 & 8.59 \\
\hline 4 & -0.751 & 2.048 & 0.01681 & 1.71 & 4 & 0.5 & -0.48 & 4.65 \\
\hline 5 & -1 & 2.4 & 15.7 & 3.52 & 2.8 & 0.65 & -0.51 & 13.54 \\
\hline
\end{tabular}

TABLE 6

Model performance compared to Özer's model using literature data (From: Ramatsoma and Chirwa, 2012)

\begin{tabular}{|l|c|c|c|c|c|c|c|c|}
\hline & \multicolumn{3}{|c|}{ Ramatsoma and Chirwa's model } & \multicolumn{4}{|c|}{ Özer's model } \\
\hline & $\begin{array}{c}r_{1} \\
\left(\times 10^{-3}\right)\end{array}$ & $r_{2}$ & $\begin{array}{c}r_{3} \\
\left(\times 10^{-3}\right)\end{array}$ & $\mathrm{SS}_{\mathrm{E}}$ & $a_{1}$ & $a_{2}$ & $a_{3}$ & $\mathrm{SS}_{\mathrm{E}}$ \\
\hline Data source et al. (2007) & -1.3 & 1.64 & 71 & 1.31 & 2.439 & 0.55 & -0.441 & 1.34 \\
\hline Reynolds and Richards (1996) & -0.76 & 2.101 & 118 & 1.49 & 1.91 & 0.55 & -0.44 & 3.72 \\
\hline Berthouex and Stevens (1982) & -1.12 & 2.307 & 540 & 1.55 & 1.938 & 0.250 & -0.633 & 0.85 \\
\hline Eckenfelder (1989) & -0.002 & 1.0009 & 79 & 6.16 & 2.365 & 0.46 & -0.428 & 6.70 \\
\hline
\end{tabular}


the fit from Eq. (10) and San's model (Table 4), shows that Ramatsoma and Chirwa's model performed better than San's model for the data produced in the laboratory and literature data from Peavy et al. (1985). For an unknown reason, San's model produced a better fit from literature data by Reynolds and Richards (1996). The initial concentration of suspended solids in the literature data by Reynolds and Richards (1996, p. 236) was slightly higher $\left(X_{o}=320 \mathrm{mg} / \mathrm{\ell}\right)$ than the initial concentration in the measured experimental data $\left(X_{o}=\right.$ approximately $112-242 \mathrm{mg} / \mathrm{\ell})$. This probably affected compaction factors resulting in different settling behaviour.

Further analysis was conducted using Özer's model and Ramatsoma and Chirwa's model. To challenge the model, a different coagulant $\left(\mathrm{FeCl}_{3}\right)$ was used at lower solids concentration. Compared to Özer's model, Ramatsoma and Chirwa's model performed much better when evaluated against experimental data and literature data, with the exception of literature data from Berthouex and Stevens (1982), (Tables 5-6). In this case, the concentrations in the data from literature were very high (up to $800 \mathrm{mg} / \ell$ ). This again appears to have affected the behaviour of the settling particles such that the semi-empirical model fell out of range of some of the interpolated data points.

\section{Model validity}

The observed order of performance in fitting experimental data was Ramatsoma and Chirwa's model $>$ San's Model $>$ Özer's model. At higher initial concentrations, San's model outperformed the Ramatsoma and Chirwa model resulting in the reversal of performance order to San's model > Ramatsoma and Chirwa's model > Özer's model. Theoretically, a rule-based (mechanistic model) is envisaged to be suitable for highly variant conditions whereas most empirical models operate well within a narrow range of conditions. This expectation was confirmed in this study by the better performance of the semi-empirical Ramatsoma and Chirwa model in the dilute to medium concentration ranges. The observed results show promise that this model could be improved to simulate the full range of concentrations including the high concentration scenario.

\section{Velocity model}

According to Je and Chang (2004), sediment suspensions at higher initial concentration aggregate at a faster rate than those at low initial concentration. This is in line with the findings of this study. It is observed in Table 2 that the addition of the coagulant (within $3 \mathrm{~min}$ ) resulted in the decrease of TSS concentration in the top part of the column and an increase of TSS concentration in the bottom part of the column. The same scenario applies for $10 \mathrm{~min}$ and $20 \mathrm{~min}$ up to $60 \mathrm{~min}$. This result is due to more frequent inter-particle collisions within the column.

If one calculates the difference between the concentration at the lowest depth $(0.25 \mathrm{~m})$ and the one at the highest depth $(1.75 \mathrm{~m})$ for all the time frames, there is a general decrease in the amount of flocs (concentration) removed with time. The TSS concentration differences are $46 \mathrm{mg} / \ell, 21 \mathrm{mg} / \ell, 33 \mathrm{mg} / \ell$, $23 \mathrm{mg} / \ell$ and $20 \mathrm{mg} / \ell$ for $10 \mathrm{~min}, 20 \mathrm{~min}, 30 \mathrm{~min}, 40 \mathrm{~min}$, $60 \mathrm{~min}$ and $80 \mathrm{~min}$, respectively. The exception with the $20 \mathrm{~min}$ concentration may be due to floc break up. A larger amount of solids was removed within the first $10 \mathrm{~min}(46 \mathrm{mg} / \ell)$, implying a high aggregation rate.

From the above reasoning, it is evident that as the floc formation increases down the column, the velocity also

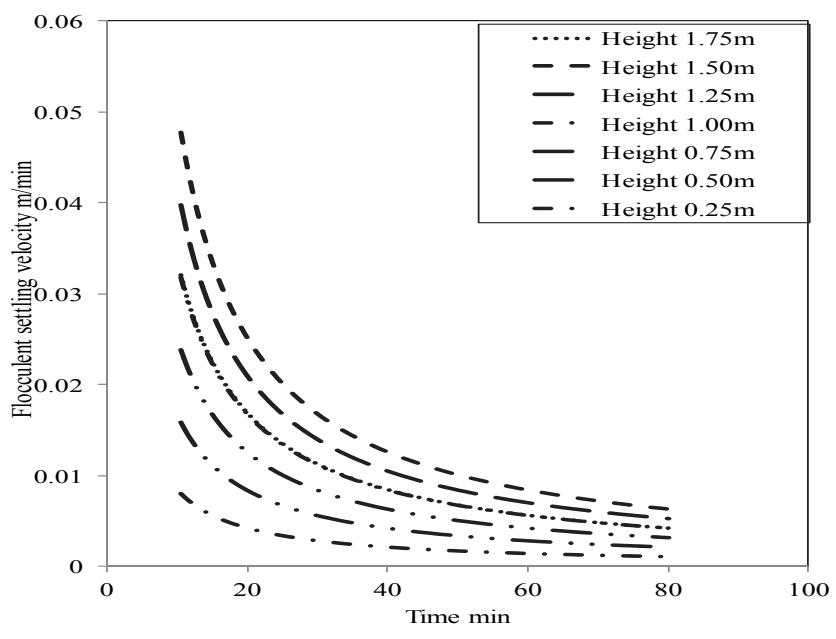

Figure 6

Settling velocity curves from the $6^{\text {th }}$ experiment, coagulant dose (10 $\left.\mathrm{mg} / \mathrm{l} \mathrm{Al}_{2}\left(\mathrm{SO}_{4}\right)_{3}\right)$, simulated by the proposed model

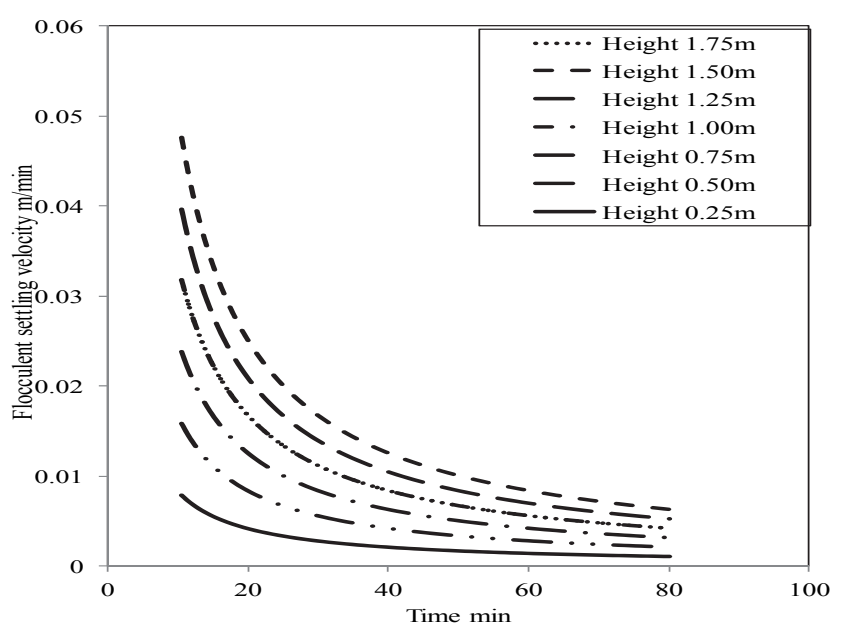

Figure 7

Settling velocity curves from the $7^{\text {th }}$ experiment, coagulant dose (15 mg/l Al $\left.\left(\mathrm{SO}_{4}\right)_{3}\right)$, simulated by the proposed model

increases. However, if one considers the instantaneous velocity, it can be noticed that the velocity at $15 \mathrm{~min}$ and a depth of $1.75 \mathrm{~m}$ is higher than the one at the same depth but at a later time, i.e. $60 \mathrm{~min}$. With time the velocity of the aggregates slows down to a lower value as the majority of larger aggregates quickly settled within the first $25 \mathrm{~min}$. By that time the column looks less turbid. Also the effect of the coagulant dose becomes less pronounced, hence a low settling velocity is inevitable with time.

The same velocity pattern is observed from Fig. (6) to Fig. (9). For instance, in Fig. (6) the velocity at height of $1.75 \mathrm{~m}$ and $10.51 \mathrm{~min}$ is $0.0478 \mathrm{~m} / \mathrm{min}$ and this decreased to 0.00629 $\mathrm{m} / \mathrm{min}$ after $80 \mathrm{~min}$. The same decline in velocity has been noticed even for literature data. The velocity for Reynolds and Richards (1996) data at a height of $1.75 \mathrm{~m}$ and $13.13 \mathrm{~min}$ is $0.0381 \mathrm{~m} / \mathrm{min}$ and decreased to $0.005089 \mathrm{~m} / \mathrm{min}$ after $99 \mathrm{~min}$. It can be concluded that as the floc size increases due to increases in collision frequency as a result of Brownian motion and differential settling, the velocity also increases, but would decrease with settling time to a lower value as the column becomes 


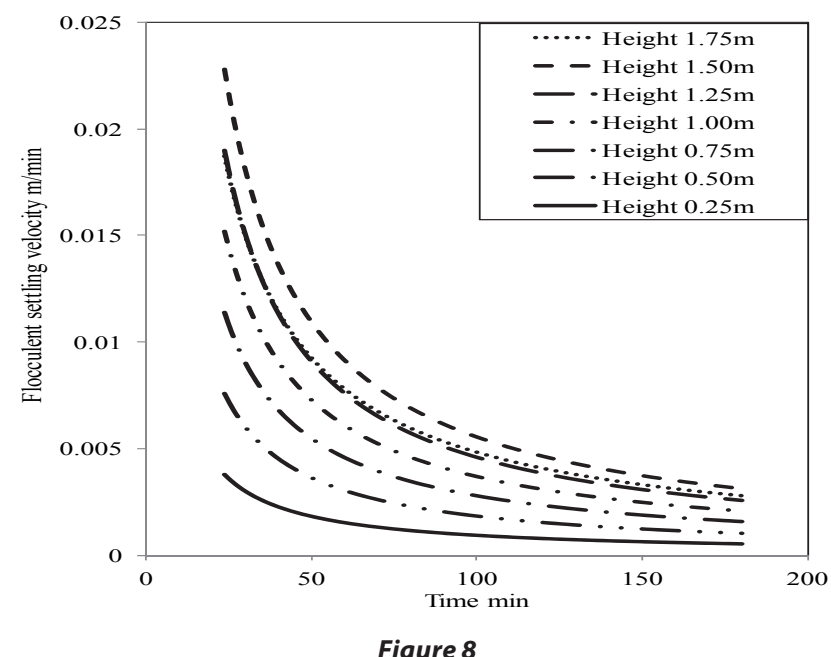

Settling velocity curves from literature data, Peavy et al (1985), simulated by the proposed model

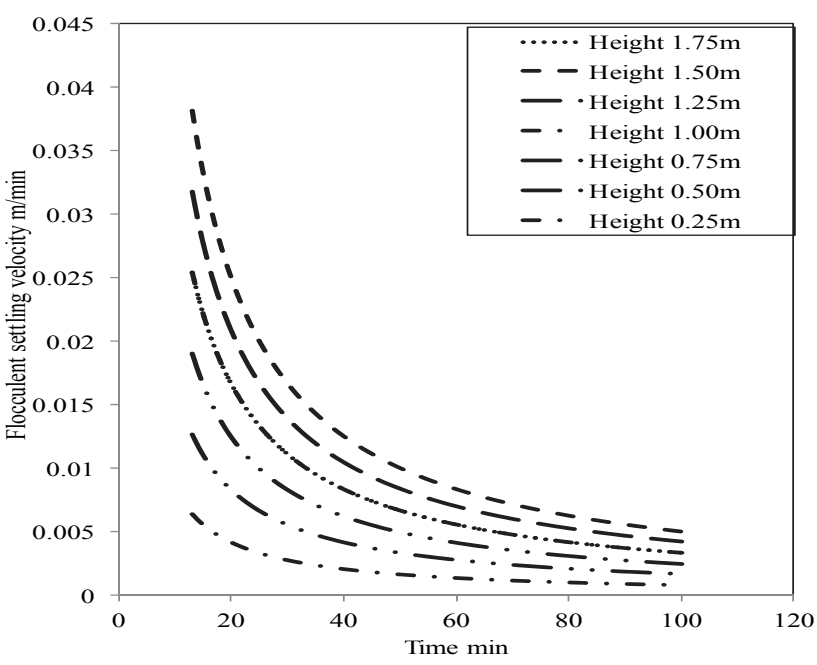

Figure 9

Settling velocity curves from literature data, Reynolds and Richards (1996), simulated by the proposed model

clearer. Hence the proposed settling velocity model can successfully determine the instantaneous velocity of flocs.

\section{CONCLUSION}

In this study, an improved model developed by Ramatsoma and Chirwa (2012) performed better than San's model and Özer's model in interpreting settling column data. Human errors due to interpolation by hand were minimised by using a reliable interpolation/optimisation algorithm to evaluate settling column data. Automation of data analysis will enable engineers and scientists to perform more advanced interpolation/optimisation schemes of settling column data to improve design accuracy. A velocity integrated equation emanating from the above model was also successfully used to determine instantaneous flocculent settling velocity of a settling particle, which is critical for design and control of sedimentation basins. The outcome was found to be in agreement with literature results in which the velocity increases due to increase in floc size. It was also noted that the velocity decreases with time as fewer and less heavy particles remain in suspension.

\section{ACKNOWLEDGEMENTS}

The research was funded partially through the National Research Foundation (NRF). Incentive Funding for Rated Researchers, Grant No. IFR2010042900080 awarded to Evans MN Chirwa of the University of Pretoria.

\section{REFERENCES}

APHA (2005) Standard Methods for the Examination of Water and Wastewater (21 ${ }^{\text {st }}$ edn.; Centennial edn.). Eaton AD, Clesceri LS, Rice EW, Greenberg AE and Franson MAH (eds.). American Public Health Association, American Water Works Association, Water Environment Federation, USA.

BERTHOUEX PM and STEVENS DK (1982) Computer analysis of settling data. J. Environ. Eng. 108 (5) 1065-1069.

CHO SH, COLIN F, SARDIN M and PROST C (1993) Settling velocity model of activated sludge. Water Res. 27 (7) 1237-1242.

HAYES GF (1992) Documentation of the SETTLE Module for ADDAMS: Design of Confined Disposal Facilities for Solids Retention and Initial Storage. USAE Waterways Experiment Station, Vicksburg, MS.

JE C and KIM K (2002) Evaluation of mathematical models for analyzing flocculent settling data Environ. Prog. 21 (4) 255-264.

JE C and CHANG S (2004) Simple approach to estimate flocculent settling velocity in a dilute suspension. Environ. Geol. 45 1002-1009.

KHELIFA A and HILL PS (2006) Models for effective density and settling velocity of flocs. Hydraul. Res. 44 (3) 90-401.

LEE DG, BONNER JS, GARTON LS, ERNEST ANS and AUTENRIETH RL (2002) Modeling coagulation kinetics incorporating fractal theories: comparison with observed data. Water Res. 36 (4) 1056-1066.

MIKKELSEN OA, HILL PS, MILLIGAN TG and CHANT RJ (2005) In situ particle size distributions and volume concentrations from a LISST-100 laser particle sizer and a digital floc camera. Cont. Shelf Res. 25 1959-1978.

MONTGOMERY R (1979) Development of a methodology for designing fine-grained dredged material sedimentation basins. Doctoral thesis, Vanderbilt University, Nashville, TN.

ÖZER A (1994) Simple equations to express settling column data. J. Environ. Eng. 120 677-682.

PACKMAN JJ, COMINGS KJ and BOOTH DB (1999) Using turbidity to determine total suspended solids in urbanizing streams in the Puget lowlands. In: Confronting Uncertainty: Managing Change in Water Resources and the Environment, Canadian Water Resources Association Annual Meeting, Vancouver, BC, 27-29 October 1999. 158-165.

PEAVY HS, ROWE DR and TCHOBANOGLOUS G (1985) Environmental Engineering. McGraw-Hill, New York.

PIRO P, CARBONE M, PENNA N and MARSALEK J (2011) Characterization of the settling process for wastewater from a combined sewer system. Water Res. 45 (20) 6615-6624.

RAMATSOMA MS and CHIRWA EMN (2012) Computational simulation of flocculent sedimentation based on experimental results. Water Sci. Technol. 65 (6) 1007-1013.

REYNOLDS TD and RICHARDS PA (1996) Unit Operations and Process in Environmental Engineering ( $2^{\text {nd }}$ edn.). International Thomson Publishing, New York.

SAN HA (1989) Analytical approach for evaluation of settling column data. J. Environ. Eng. 115 (2) 455-461.

SAWYER CN, McCARTHY PL and PARKIN GF (2003) Chemistry for Environmental Engineering ( $5^{\text {th }}$ edn.). McGraw-Hill, New York.

TCHOBANOGLOUS G, BURTON F and STENSEL HD (eds.) (2003) Wastewater Engineering ( $4^{\text {th }}$ edn.). Metcalf \& Eddy, Inc., McGrawHill, New York.

XU F, WANG DP and RIEMER N (2008) Modelling flocculation processes of fine-grained particles using a size resolved method: Comparison with published laboratory experiments. Cont. Shelf Res. 28 2668-2677. 